\title{
A Study on the Performance of Segment Used for Power Duct Applying the Lattice Beam Rebar Net
}

\author{
Jeyoung Park, Sungwook Hwang, and Youngshik Park
}

\begin{abstract}
This study was performed for the segment lining, an underground structure. Rebar of existing segment is designed in the form of lattice, so the rebar is influenced by the stress of segment. The existing segment designed before the introduction of optimal design concept is evaluated as the over design up to the year of 2018.

In this study, we performed the tests intending to evaluate the structural performance of segment with an external diameter of $\emptyset 3400$ by transforming the shape of internal rebar net. We plan to perform additional design work focusing on the optimized segment based on the results of these tests.
\end{abstract}

Index Terms -Segment, lattice beam, lining, power duct.

\section{INTRODUCTION}

The tunnel work using the shield TBM, a construction method used to form a lining in the tunnel or power duct upon excavation after carrying in the segment fabricated in the form of precast concrete from the factory, is the special construction method developed focusing on the minimization of damage to the downtown and residential area by reducing the vibration and noise expected when applying the existing conventional tunnel construction method. Unlike the existing tunnel work performed through many processes such as carrying in the ready-mixed concrete, shotcrete spray and curing process after the blasting, this construction method is applicable to the diverse geological conditions and actualizes the continuity of work by ensuring the stability against the collapse of tunnel by means of installing the segment fabricated with the precast concrete at the same time as the machine excavation.

The cost of segment, about $25 \sim 40 \%$ of shield tunnel direct construction cost, including the dynamical and structural importance of segment, occupies the biggest portion of construction cost [1]. Especially, the weight of segment occupied in the shield tunnel direct construction cost is getting increased if the cross section of shield tunnel is increased and construction duration is extended.

In this regard, technical development intending to save the segment fabricating cost by improving the performance of segment is actively performed in the developed countries as a part of plan to save the construction cost of shield tunnel. A plan to reduce the thickness of segment using the high strength concrete or super high strength concrete has been continually studied in Japan, and the composite

Manuscript received April 23, 2018, revised June 19, 2018.

Jeyoung Park is with the ISDongseo/Technology Institute, Seoul, Korea (e-mail: jypark@isdongseo.co.kr).

Sungwook Hwang and Youngshik Park are with ISDongseo/Technology Institute, Seoul, Korea (e-mail: rokmc882@isdongseo.co.kr; 210039@isdongseo.co.kr). segment and ductile segment are being developed as well [2]. The high performance segment to save the segment fabricating cost and improve the durability has been developed in Europe through the TUNCONSTUCT Project, European joint research project [3]. Recently, the steel-fiber reinforced concrete segment is developed and widely used as a technical alternative to omit or minimize the rebar [4], [5].

A part of research cases has been reported about the numerical analysis research of segment lining in Korea [6], [7], [8]. However, material and structural research about the saving of segment fabricating cost and improvement of performance is relatively insufficient.

In this study, we therefore fabricated the segment prototype using the lattice beam type rebar net reducing the volume of rebar by transforming the shape of rebar net using the high tensile rebar showing the design yield strength of $500 \mathrm{MPa}$ in order to reinforce the basic concrete showing the design strength of $42 \mathrm{MPa}$ as a part of technical plan to save the segment fabricating cost. We also plan to verify the performance of new shape segment prototype fabricated by making comparison with the dynamic behavior characteristics of existing segment by means of changing the shape and arrangement.

\section{MAKING SPECIMENS AND EXPERIMENT METHOD}

In this study, we fabricated the segment lining A Type with an external diameter of $3,400 \mathrm{~m}$, length of $2,392 \mathrm{~mm}$ and width of $1,200 \mathrm{~mm}$, which was used for the power duct installed in the western part of metropolitan area as the specimens for the load test as shown in the Fig. 1, 2.

At this time, we fabricated a mockup specimen of high strength segment using the rebar showing the design strength of $500 \mathrm{MPa}$ and shape of lattice beam for the concrete showing the design strength of $42 \mathrm{MPa}$ in order to reduce the volume of rebar. For the comparison of performance with the high strength segment of new shape fabricated through the above procedure, we had a plan to fabricate the mockup specimens of segments (Cases 1 5) by changing the yield strengths of current segment (Case 6) with its concrete design strength of $42 \mathrm{MPa}$ and its rebar's design yield strength of 400MPa (SD400) and shape of rebar net and then compare the performances of Case 6 and Cases $1 \sim 5$.

We measured the yield strengths and diameters of each rebar in consideration of different fabricating conditions as shown in the Table I. The distributing bar and bolt box were arranged at the same location excluding the current segment (Case 6). For the lattice beam (Fig. 3), a main item of this study, the diameters of top main rebar and bottom rebar were $16 \mathrm{~mm}$ and $19 \mathrm{~mm}$, and the same diameters were 
applied to all cases (Fig. 4 and 5).

Especially, the cost was reduced up to $23 \%$ as compared with the one of current segment depending on the arrangement and diameter of rebar, so the effect of saving the cost of rebar required for the fabrication of segment are expected because of decreased main rebar.

\begin{tabular}{|c|c|c|c|c|c|c|}
\hline \multirow{2}{*}{$\begin{array}{l}\text { Speci } \\
\text { mens }\end{array}$} & \multicolumn{2}{|c|}{ Main rebar } & \multicolumn{2}{|c|}{$\begin{array}{l}\text { Distribution } \\
\text { rebar }\end{array}$} & \multicolumn{2}{|c|}{ Lattice rebar } \\
\hline & $\begin{array}{c}\text { nam } \\
\mathrm{e}\end{array}$ & $\begin{array}{l}\text { Strng } \\
(\mathrm{MPa})\end{array}$ & $\begin{array}{c}\text { nam } \\
\mathrm{e}\end{array}$ & $\begin{array}{l}\text { Strng } \\
(\mathrm{MPa})\end{array}$ & name & $\begin{array}{l}\text { Strng } \\
\text { (MP) }\end{array}$ \\
\hline Case1 & \multirow{5}{*}{ H19 } & \multirow{5}{*}{500} & \multirow{6}{*}{ H16 } & \multirow{5}{*}{500} & \multirow{3}{*}{ H13 } & 400 \\
\hline Case2 & & & & & & 400 \\
\hline Case 3 & & & & & & 400 \\
\hline Case 4 & & & & & \multirow{2}{*}{$\varnothing 6$} & 400 \\
\hline Case5 & & & & & & 400 \\
\hline Case6 & H16 & 400 & & 400 & - & - \\
\hline
\end{tabular}

하 부 평 면 도

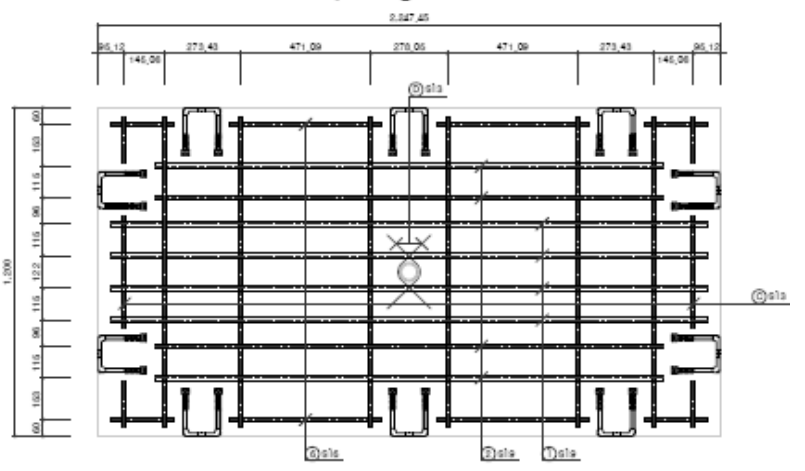

Fig 1. Reinforcement drawing (bottom).

상부 평 면도
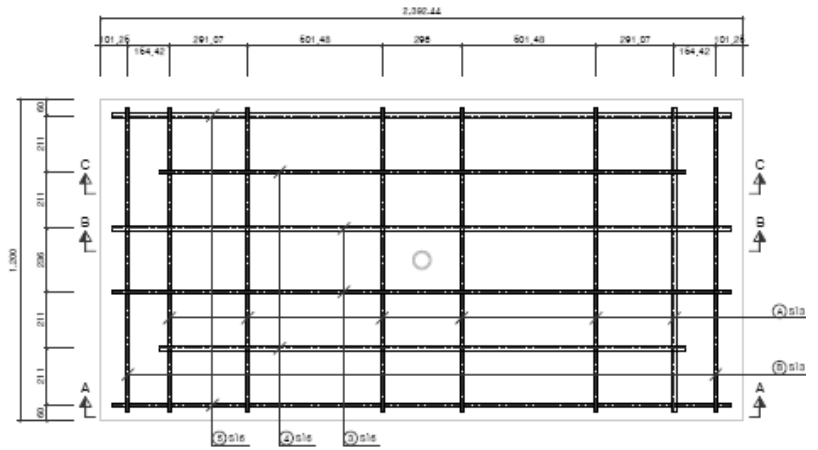

Fig 2. Reinforcement drawing (top).

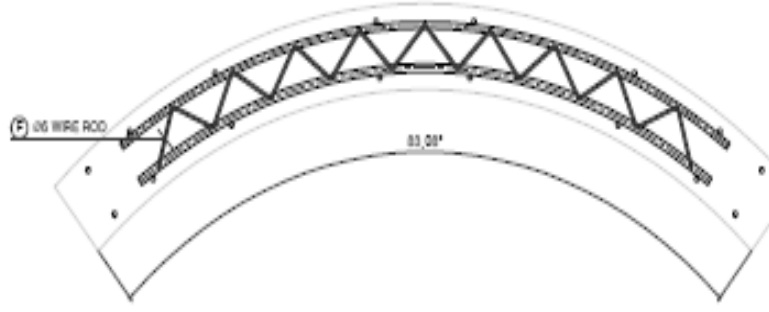

Fig 3. Lattice bar drawing.
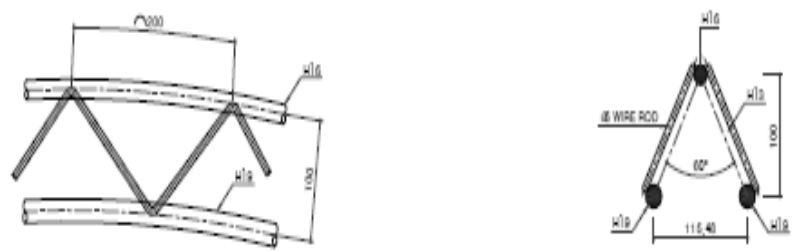

Fig 4. Lattice bar detail.
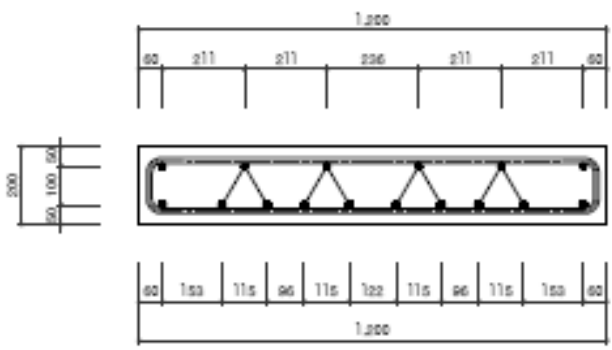

Fig. 5. Arrangement of lattice bar.

All twelve specimens were fabricated for this study. While two (2) specimens were fabricated for the existing segment, Case 6, using the current method, ten (10) specimens were fabricated for the Cases $1 \sim 5$ using the new shape rebar net of lattice beam (Fig. 6). The following Table II shows the summary of fabricated specimens:

TABEL II: VARIABLES OF SPECIMENS

\begin{tabular}{|c|c|c|c|c|c|}
\hline Spec. & No. & Lattice & Arrangem. & Weigh. & $\begin{array}{l}\text { Ratio } \\
\text { decre }\end{array}$ \\
\hline Case1 & \multirow{6}{*}{$2 \mathrm{EA}$} & \multirow{3}{*}{ D13 } & $\Delta \boldsymbol{\Delta} \Delta \boldsymbol{\Delta}$ & $100 \mathrm{~kg}$ & $-10 \%$ \\
\hline Case2 & & & $\Delta \nabla \nabla \Delta$ & $100 \mathrm{~kg}$ & $-10 \%$ \\
\hline Case3 & & & $\Delta \nabla \Delta \Delta \nabla \Delta$ & $130 \mathrm{~kg}$ & $+18 \%$ \\
\hline Case4 & & \multirow{2}{*}{ D6 } & $\Delta \Delta \Delta \Delta$ & $85 \mathrm{~kg}$ & $-23 \%$ \\
\hline Case5 & & & $\nabla \nabla r \nabla$ & $87 \mathrm{~kg}$ & $-21 \%$ \\
\hline Case6 & & - & - & $110 \mathrm{~kg}$ & $0 \%$ \\
\hline
\end{tabular}

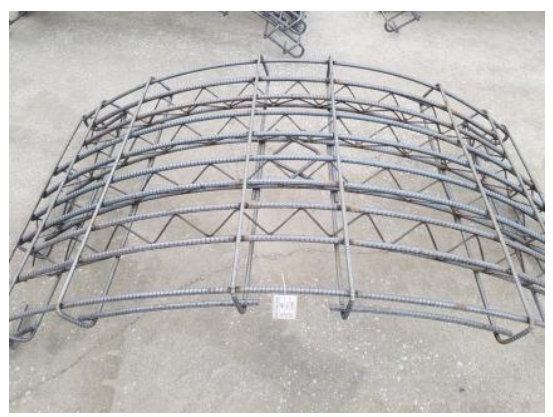

(a) Reinforcing net production.

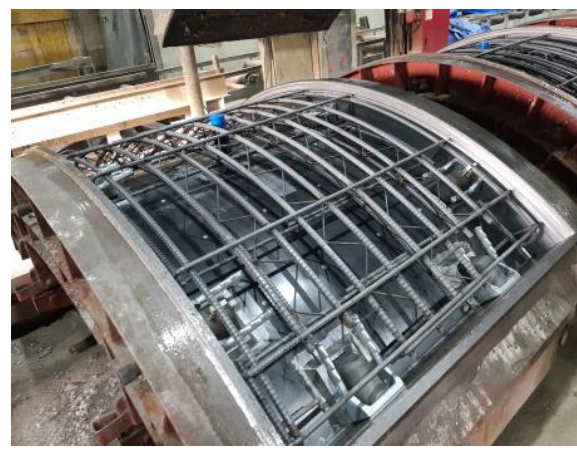

(b) Reinforcing net placement.

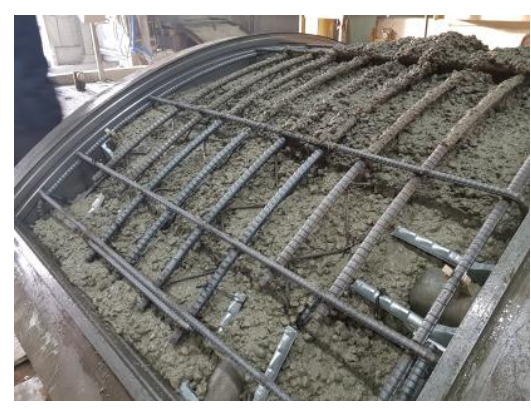

(c) Concrete pouring 


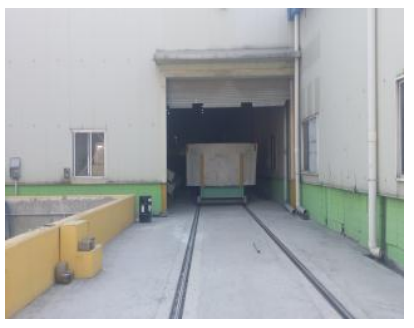

(d) Inputting in the steam curing room.

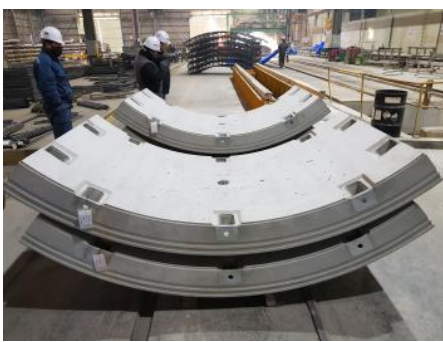

(e) Demolding and field.

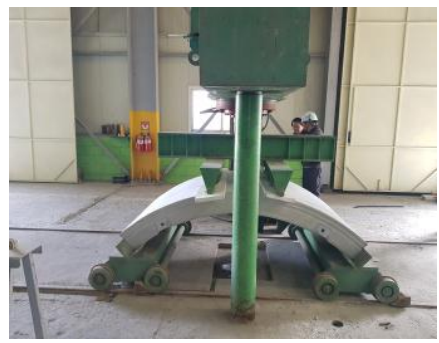

(f) Conducting experiments.

Fig. 6. The production process of the segments used in this experiment.

The tail void inevitably occurs between the excavation surface and segment due to the structural characteristics of shield TBM when excavating the ground using the shield TBM. If the tail void is left without taking appropriate actions, excessive ground subsidence occurs, so the backfill grouting work required for tightly filling the tail void immediately after the excavation must be performed in order to integrate the segment lining and excavated ground.

If the tail void remains on the external surface of segment because of unsatisfactory grouting work, big stress concentration occurs on the segment as shown in the Figure 10 , so it may reduce the structural stability of segment. Therefore, the bending test intending to show the unsatisfactory working condition is the most typical and common test performed for evaluating the performance of segment.

The bending test of segment is classified into the bending test for the segment itself and bending test for the joint. Checking the performance of segment joint is not the purpose of this study, so we have performed only the bending test for the segment itself.

The loading system with the maximum capacity of 100 tons was used as the test equipment for the mockup bending test of segment, and the hydraulic controller enabling the control of load was included into this loading system. The bottom of loading system was designed as the rigger in the form of rail so that the big specimen may be transferred. Especially, the loading test was performed under the condition of fixing the bottom roller base because The loading test was performed provided that the bottom roller base was fixed because the segment was actually installed at the site with fixed (for the details, refer to the Fig. 10).

All tests were performed under the condition of controlling the load, and the test was performed at the loading speed of $60 \mathrm{kN} / \mathrm{min}$ by setting the time when the loading plate contacts the top of segment as the zero.

In this study, the hydraulic controller (maximum loading capacity: 100 tons and maximum stroke: $500 \mathrm{~mm}$ ) installed at the center of loading system was used for loading the top of specimen during the mockup bending test of segment. We performed 4-point bending test for the segment after attaching two top rollers with a span of $400 \mathrm{~mm}$ to the bottom of hydraulic controller and installing the roller base with its span set to $2,247 \mathrm{~mm}$ to be suitable for the size of segment shown in the Fig. 1 (for the details, refer to the Fig. 7 and 8).

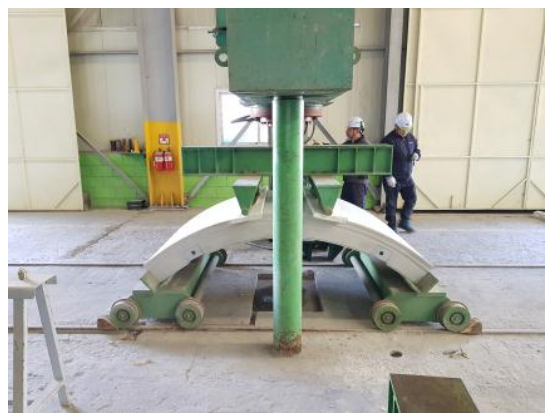

Fig. 7. Bending test performed for the mockup specimen of segment.

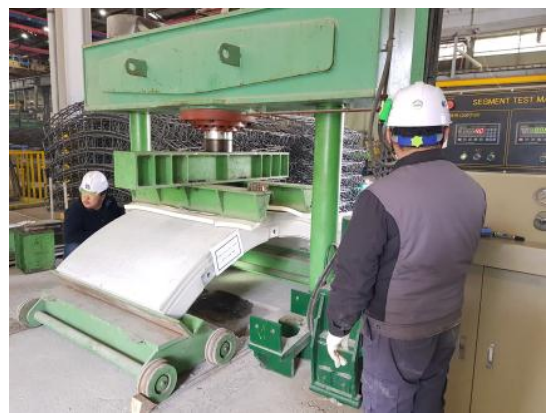

Fig. 8. Roller based installed on the bottom of segment specimen.

TABEL III: RESULTS OF TEST

\begin{tabular}{|c|c|c|c|c|}
\hline Case & $\begin{array}{c}\text { Early } \\
\text { Crack }(\mathrm{kN})\end{array}$ & $\begin{array}{l}\text { Displacement } \\
(\mathrm{mm})\end{array}$ & $\begin{array}{l}\text { Strength } \\
(\mathrm{kN})\end{array}$ & $\begin{array}{c}\text { Average } \\
(\mathrm{kN})\end{array}$ \\
\hline \multirow{2}{*}{ Case 1} & 80 & 26.7 & 440 & \multirow{2}{*}{471.0} \\
\hline & 82 & 25.0 & 502 & \\
\hline \multirow{2}{*}{ Case 2} & 68 & 24.0 & 388 & \multirow{2}{*}{402.5} \\
\hline & 71 & 25.0 & 417 & \\
\hline \multirow{2}{*}{ Case 3} & 81 & 24.0 & 531 & \multirow{2}{*}{527.0} \\
\hline & 80 & 25.0 & 523 & \\
\hline \multirow{2}{*}{ Case 4} & 71 & 30.0 & 461 & \multirow{2}{*}{463.5} \\
\hline & 63 & 25.0 & 466 & \\
\hline \multirow{2}{*}{ Case 5} & 80 & 25.0 & 240 & \multirow{2}{*}{245.0} \\
\hline & 74 & 30.0 & 250 & \\
\hline \multirow{2}{*}{ Case 6} & 76 & 26.0 & 410 & \multirow{2}{*}{401.5} \\
\hline & 81 & 23.0 & 393 & \\
\hline
\end{tabular}




\section{RESULTS ANALYSIS OF SEGMENT EXPERIMENT}

The results of mockup bending test performed for the existing segment fabricated using the general rebar net with a concrete design strength of $42 \mathrm{MPa}$ showed that the initial crack was initiated and neutral axis moved up at the load of $78 \mathrm{kN}$, compressive side rebar behaved as the tensile rebar at the condition of design breaking load, and the specimen of Case 6 indicated the behavior close to the plastic failure after the design breaking load. The plastic deformation was measured as $26 \mathrm{~mm}$, and the specimen was destructed by the crush destruction of compressive side concrete at the loading load of $401.5 \mathrm{kN}$. (for the details, refer to the Table III).
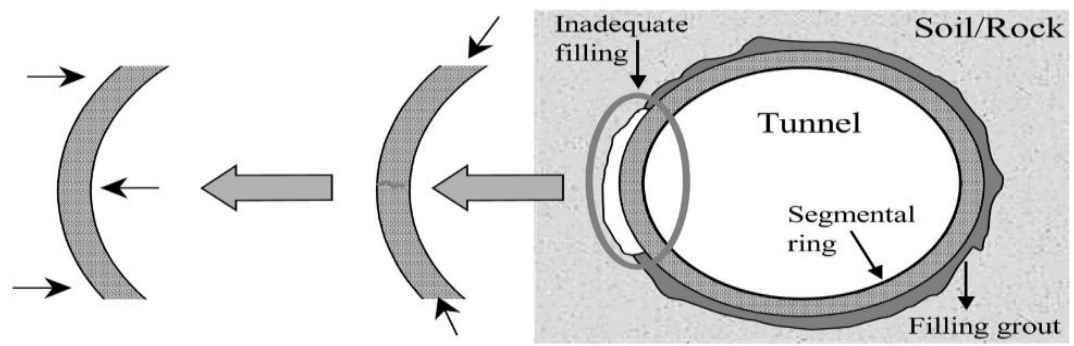

Fig. 9. Importance of bending test in evaluating the performance of segment lining [9].

The following showed the results of test (Cases $1 \sim 5$ ) using the rebar net instead of existing rebar net: The specimen of Case 1 was fabricated so that the lattice beams were arranged in 4 rows to the forward direction. For the shape of all lattice beams, top rebar and bottom rebar were designated as the D16 and D19 respectively. The lattice type rebar was installed with cut without being connected to the D13, and the contact surfaces with the top main rebar and bottom rebar were measured as $70 \mathrm{~mm}$ and $50 \mathrm{~mm}$, and these two rebars were combined by welding two contact surfaces. The weights of general segment lattice type rebar net (Case 6) and Case 1 were measured as $110 \mathrm{~kg}$ and $100 \mathrm{~kg}$, so the results showed that the specimen of Case 1 decreased the volume of rebar up to $10 \%$ as compared with the Case 6 . The results of test performed for the specimen of Case 1 showed that the plastic deformation was about $27 \mathrm{~mm}$, load causing the crack was $81 \mathrm{kN}$ and breaking load was 471.0 $\mathrm{kN}$.

The specimen of Case 2 was fabricated so that the lattice beams were arranged in 4 rows to the backward direction and forward direction. The weights of general segment lattice type rebar net (Case 6) and Case 2 were measured as $110 \mathrm{~kg}$ and $100 \mathrm{~kg}$, so the results showed that the specimen of Case 2 decreased the volume of rebar up to $10 \%$ as compared with the Case 6 . The effect of saving the volume of rebar was same as the Case 1 because only the arrangement of lattice bar was changed and there was no difference in the volume of rebar. The results of test performed for the specimen of Case 2 showed that the plastic deformation was about $24 \mathrm{~mm}$, load causing the crack was $70 \mathrm{kN}$ and breaking load was $402.5 \mathrm{kN}$.

The specimen of Case 3 was fabricated so that the lattice beams were arranged in 6 rows to the backward direction and forward direction. The weights of general segment lattice type rebar net (Case 6) and Case 3 were measured as $110 \mathrm{~kg}$ and $130 \mathrm{~kg}$, so the results showed that the specimen of Case 3 increased the volume of rebar up to $18 \%$ as compared with the existing rebar net. The volume of rebar was increased because the specimen was fabricated as the lattice arrangement of 6 rows by adding two rows to the existing four rows. The results of test performed for the specimen of Case 3 showed that the plastic deformation was about $25 \mathrm{~mm}$, load causing the crack was $80 \mathrm{kN}$ and breaking load was $527.0 \mathrm{kN}$.

The specimens of Case 4 and Case 5 differ from the ones of Cases $1 \sim 3$ because the general steel wire of $\varnothing 6$ was used as the material of lattice instead of rebar, so the specimens considerably decreased the volume of rebar as compared with the specimens of other lattice beam type. The specimen of Case 4 was fabricated so that the lattice beams were arranged in 4 rows to the forward direction. The weights of Case 4 were measured as $85 \mathrm{~kg}$, so the results showed that the specimen of Case 4 decreased the volume of rebar up to $23 \%$ as compared with the existing rebar net. The effect of saving the volume of rebar was resulted from the use of general steel wire of $\varnothing 6$ instead of deformed bar. The results of test performed for the specimen of Case 4 showed that the plastic deformation was about $30 \mathrm{~mm}$, load causing the crack was $71 \mathrm{kN}$ and breaking load was $463.5 \mathrm{kN}$.

The specimen of Case 5 was fabricated so that the lattice beams were arranged in 4 rows to the backward direction. The weights of Case 5 were measured as $87 \mathrm{~kg}$, so the results showed that the specimen of Case 5 decreased the volume of rebar up to $21 \%$ as compared with the existing rebar net. The effect of saving the volume of rebar was resulted from the use of general steel wire of $\varnothing 6$ like the Case 4. The results of test performed for the specimen of Case 5 showed that the plastic deformation was about $25 \mathrm{~mm}$, load causing the crack was $78 \mathrm{kN}$ and breaking load was $245.0 \mathrm{kN}$.

Pictures of the destroyed specimens refer to the Fig. 10.

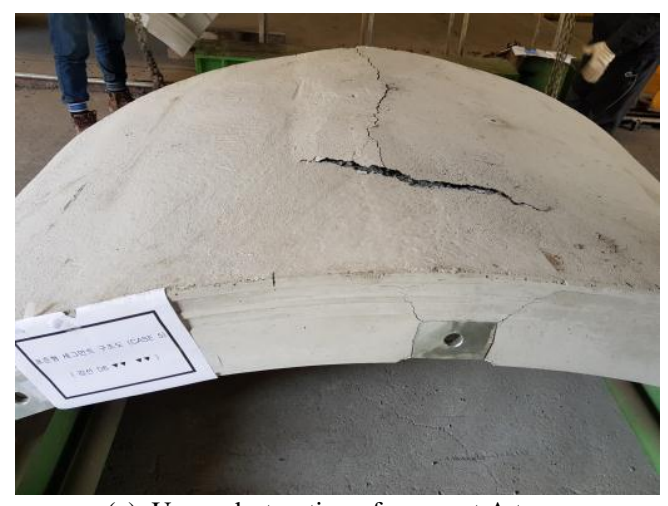

(a). Upper destruction of segment A type. 


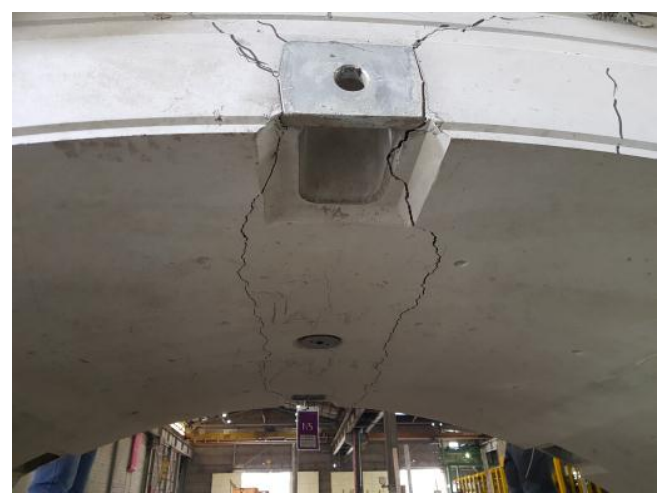

(b). Bottom destruction of segment a type.

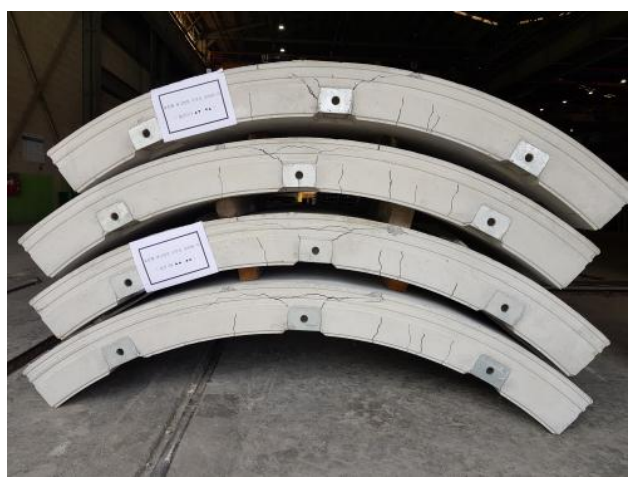

(c). Piled-up Destroyed segment a type Fig. 10. Destroyed specimens.

\section{CONCLUSIONS}

In this study, we have fabricated the new shape rebar net in the form of lattice beam in order to compare with the current segment fabricated by the general concrete and rebar net and then performed the bending test intending to analyze the dynamic behavior of new shape rebar. Important results obtained through this study are summarized as follows:

1) While the results of bending test performed for the general A Type segment lining of lattice type rebar net with an external diameter of $3.40 \mathrm{~m}$ and concrete design strength of $42 \mathrm{MPa}$ show the value of $401.5 \mathrm{kN}$, results of bending test performed for the Cases $1 \sim 3$ fabricated using the new rebar in the form of lattice beam show the value of $466.8 \mathrm{kN}$, so the performance of Cases $1 \sim 3$ is $16 \%$ higher than the one of existing segments. The results of bending test performed for the Cases 4 and 5 show that the performance of Cases 4 and 5 are higher or lower than the one of existing segment.

2) We have performed the diverse tests for the Cases 1 5 fabricated using the new shape rebar net in the form of lattice beam. The results of test show that the volume of material may be considerably reduced up to the level of $23 \%$ if the steel wire is used instead of rebar, and the processing of steel wire is easier than the one of rebar, so the Case 4 is evaluated as the optimal alternative in consideration of cost and performance compared with the ones of existing segment.

3) Case 5 was fabricated using the same rebar volume and lattice beam as the ones of Case 4. However, the performance of Case 5 evaluated as the $245.0 \mathrm{kN}$ was $52 \%$ lower than the one of Case 4 evaluated as the $463.5 \mathrm{kN}$. This difference was resulted from the arrangement of main rebar fabricated in the form of lattice beam. While eight (8) main rebars were arranged in the bottom tensile axis of Case 4, only four (4) main rebars were arranged in the Case 5 with its lattice beam overturned, so the performance of Case 5 was lower than the one of Case 4.

4) The crush destruction on the top compressive part resulted from the top loading and destruction resulted from the tensile crack of tensile part were clearly observed. Especially, the crack frequently occurs around the bolt box of bottom tensile part. This crack was resulted from the difference between the concrete and other materials. However, the impact resulted from the bolt box is offset upon installation at the site, so the impact observed during the test is expected to become low at the site. The performance expected at the site would be better than the one observed during the test.

5) The results of measuring the permanent deformation resulted from the plastic failure showed that the specimen was destructed displaying the deformation of $25 \mathrm{~mm} \sim 30 \mathrm{~mm}$. The initial crack was visually observed when applying the load of $70 \sim 80 \mathrm{kN}$. This value was the value applicable during the visual observation. However, the initial crack was expected to occur on the actual member when the load of about 56 $\mathrm{kN}$ was applied if defining the tensile strength of concrete as the $1 / 10$ of compressive strength in consideration of actual strength of 56MPa expected at the concrete design strength of $42 \mathrm{MPa}$.

6) The results of mockup bending test showed that the rebar net of lattice beam type improved the performance up to $16.1 \%$ as compared with the existing segment excluding the Case 5 and Case 3 in terms of performance and volume of rebar, and the volume of rebar was decreased up to $16 \%$. In other words, the performance was improved up to $16.1 \%$ even if the volume of rebar was decreased up to $16 \%$. The results of test performed for the Case 4 showed that the volume of rebar was decreased up to $23 \%$ and load carrying capacity of segment was considerably improved up to $15.44 \%$ by changing the shape of rebar net.

\section{ACKNOWLEDGMENT}

This research was supported in part by a grant (17SCIPB128706-01) from Construction Technology Research Program funded by the Ministry of Land, Infrastructure and Transport of Korean Government and the Korea Agency for Infrastructure Technology Advancement (KAIA).

\section{REFERENCES}

[1] Standard Tunnel Specification prepared by the Korea Federation of Tunnel Engineering and issued, the Ministry of Land, Transport and Marine Affairs (2009), pp. 110-113.

[2] W. Takashi, T. Toshiharu, A. Tsuyoshi, and M. Katsuhiko, "Development of a new composite structure segment for large diameter shield tunnel," Tunnelling and Underground Space Technology, vol. 19, pp. 449-450, 2004.

[3] G. Beer, Technology Innovation in Underground Construction, CRC Press, pp. 299-314, 2010.

[4] T. Kasper, C. Edvardsen, G. Wittneben, and D. Neumann, "Lining design for the district heating tunnel in Copenhagen with steel fiber 
reinforced concrete segments," Tunneling and Underground Space Technology, vol. 23, pp. 574-587.

[5] G. Tiberti and G. A. Plizzari, "Parametric study on tunnel linings in fiber reinforced concrete combined with traditional reinforcement," in Proc. WTC 2009, Budapest, Hungary, Paper No.O-08-09.

[6] K. Kwang-Jin, K. Sung-Yil, C. Seuk-Yeun, and K. Jong-Soo, "Theoretical and numerical study on the support pressure for tunnel face stability in shield TBM construction," Korean Tunelling and Underground Space Association, vol. 8, no. 3, pp. 197-204, 2006.

[7] K. Jung-Hyun and K. Kyung-Jin, "Study on improving method of arranging trapezoidal pre-cast segment lining in shield tunnel," Korean Tunelling and Underground Space Association, vol. 9, no. 1, pp. 1-18, Mar, 2007.

[8] S. Jong-Ho, S. Yong-Suk, P. Dong-In, C. Sung-Eun, and C. KyuHoon, "A study on hydraulic behaviour and leakage control of segment linings using the numerical method," Korean Tunelling and Underground Space Association, vol. 11, no. 2, pp. 131-140, Jun, 2009.

[9] R. Gettu, B. Barragán, T. García, G. Ramos, C. Fernández, and R. Oliver, "Steel fiber reinforced concrete for the Barcelona Metro Ling 9 tunnel lining," in Proc. the 6th RILEM Symposium on FRC, Varenna, Italy, RILEM PRO 39, pp. 141-156, 2004.

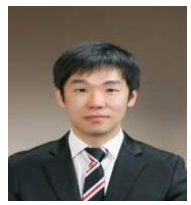

Je Young Park was born on February 28, 1985 and obtained the master's degree based on the thesis "A study on behavior of PPSC beam using GFRP Rebar" on or before the graduation from the department of civil engineering, Hanyang University. After the graduation, performed the test and research works for high-rise complex building project group as a member of Research Institute of Industrial Science and Technology (RIST) and POSCO since 2013. From the year of 2015, performed the national projects such as 'Application Technologies for impact and blast resistant structure using high performance fiber reinforced cementitious composites' and 'Development of high-insulation materials using nanoaerogel and aerated concrete' and company projects such as power duct
PC Segment new product development project as a researcher of concrete technology institute of IS Dongseo Co., Ltd.

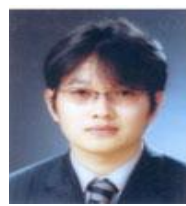

SungWook Hwang was born on November 15, 1980 in Masan, Korea and obtained the master's degree based on the thesis "Behavior of loaded pile for calibration chamber tests" on or before the graduation from the department of civil engineering, Yonsei University. After the graduation, worked for the Korea Railroad Research Institute for 2 or 3 years. Since 2012, performed the national projects such as 'Application Technologies for impact and blast resistant structure using high performance fiber reinforced cementitious composites' and 'Development of high-insulation materials using nano-aerogel and aerated concrete' and company projects such as power duct PC Segment new product development project as a researcher of concrete technology institute of IS Dongseo Co., Ltd.

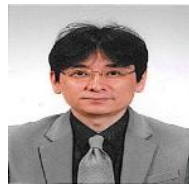

YoungShik Park was born on September 02, 1965 in Daegu and obtained the doctor's degree based on the thesis "Experimental study on the sulfate attack of high strength concrete and end treatment method" on or before the graduation from the department of civil engineering, Yeungnam University. After the graduation, worked as the research chief and professor of Kundong University. Since 2010, performed the national projects such as 'Application Technologies for impact and blast resistant structure using high performance fiber reinforced cementitious composites' and 'Development of high-insulation materials using nano-aerogel and aerated concrete' and company projects such as power duct PC Segment new product development project as a chief of concrete technology institute of IS Dongseo Co., Ltd. 